\title{
Erratum to: Influence of climate warming and resin collection on the growth of Masson pine (Pinus massoniana) in a subtropical forest, southern China
}

\author{
Feng Chen $^{1,2} \cdot$ Yu-jiang Yuan ${ }^{1,2} \cdot$ Shu-long Yu ${ }^{1,2} \cdot$ Tong-wen Zhang ${ }^{1,2}$
}

Published online: 30 October 2015

(C) Springer-Verlag Berlin Heidelberg 2015

\section{Erratum to: Trees (2015) 29:1423-1430 \\ DOI 10.1007/s00468-015-1222-3}

The original version of Fig. 8 was first published in "Papadopoulos AM (2013) Resin Tapping History of an Aleppo Pine Forest in Central Greece. The Open Forest Science Journal, 6 (Suppl 1: M5), pp 50-53" under the terms of the Creative Commons Attribution Non-Commercial License (http://creativecommons.org/licenses/bync/3.0/legalcode).

The figure was copied and modified without including appropriate reference to the original author and article. The new figure labeling is erroneous and the legend is misleading. The figure shows a cross section of Pinus halepensis Mill, not Pinus massoniana, and the wound occurred before 1995 .

The authors regret this error and apologize for any confusion and inconvenience this may have caused.

The online version of the original article can be found under doi:10.1007/s00468-015-1222-3.

Feng Chen

feng653@163.com

1 Key Laboratory of Tree-ring Physical and Chemical Research of China Meteorological Administration, Institute of Desert Meteorology, China Meteorological Administration, 46 Jianguo Road, Urumqi 830002, China

2 Xinjiang Laboratory of Tree-ring Ecology, Institute of Desert Meteorology, China Meteorological Administration, 46 Jianguo Road, Urumqi 830002, China 